\title{
Immune and targeted therapy for cancer: time to rethink restrictions for the treatment of the elderly and frail
}

Terapia direcionada e imunológica para o câncer: hora de repensar as restrições para o tratamento de idosos e frágeis

Juliana Rodrigues Beal' ${ }^{1}$, Gustavo Schvartsman ${ }^{1}$, Rodrigo Ramella Munhoz ${ }^{2}$, Theodora Karnakis ${ }^{3}$, Rafael Aliosha Kaliks'

\begin{abstract}
Targeted and immunotherapy have revolutionized cancer treatment. They safely substitute for traditional chemotherapy in a significant and growing number of malignancies. In this article, we review the United States Food and Drug Administration (FDA) - approved targeted and immunotherapies, currently used in oncology and compare their safety and efficacy in young versus geriatric and frail sub-population. The results suggest an overall comparable, if not superior efficacy in several tumor types, with acceptable toxicities across the board compared to cytotoxic chemotherapy and a favorable analysis in the comparison to the results observed in the younger population. The very decision to place elderly patients on exclusive palliative care can no longer be supported based on age or frailty alone. The historical concept of medical oncologists leaning for palliative treatments for these patients needs to be revisited.
\end{abstract}

Keywords: Molecular targeted therapy; Immunotherapy; Therapeutics; Frail elderly; Aged.

1. Hospital Israelita Albert Einstein, Medical Oncology - São Paulo - SP - Brazil.

2. Hospital Sírio-Libanes, Medical Oncology - São Paulo - SP - Brazil.

3. Universidade de São Paulo, Geriatrics - São Paulo - SP - Brazil.

Financial support: none to declare.

Conflicts of interest: The authors declare no conflict of interest relevant to this manuscript.

Correspondence author: Rafael Aliosha Kaliks, Hospital Israelita Albert Einstein, Medical Oncology - São Paulo - SP - Brazil.

Av. Albert Einstein, 627 - Jardim Leonor, São Paulo, SP, Brazil. Zip code: 05652-900.

E-mail: rkaliks@gmail.com 


\section{RESUMO}

A imunoterapia direcionada revolucionou o tratamento do câncer. Eles substituem com segurança a quimioterapia tradicional em um número significativo e crescente de doenças malignas. Neste artigo, revisamos a Food and Drug Administration (FDA) - imunoterapias direcionadas aprovadas atualmente usadas em oncologia, e comparamos sua segurança e eficácia na subpopulação jovem versus geriátrica e frágil. Com resultados sugerindo uma eficácia geral comparável, se não superior, em vários tipos de tumor com toxicidades aceitáveis em toda a linha em comparação com a quimioterapia citotóxica, e uma análise favorável na comparação com os resultados observados na população mais jovem. A própria decisão de colocar pacientes idosos em cuidados paliativos exclusivos não pode mais ser sustentada apenas com base na idade ou fragilidade. O conceito histórico de médicos oncologistas que buscam tratamentos paliativos para esses pacientes precisa ser revisitado.

Descritores: Terapia de alvo molecular; Imunoterapia; Terapêutica; Idoso frágil; Envelhecido.

\section{INTRODUCTION}

Ageing is one of the major risk factors for cancer development. ${ }^{1}$ Although ageing can occur in increasingly healthier conditions, it is often associated with a growing number of comorbidities and eventually leads to frailty. ${ }^{2}$ The combination of these three factors (advanced age, comorbidities, and frailty) has historically been a major determinant in the exclusion of such patients from most registration trials in medical oncology. In addition, treatment modalities such as intensive chemotherapy, bone marrow transplantation, high- dose interleukin-2, biochemotherapy, intraperitoneal hyperthermic chemotherapy, and major surgeries such as cystectomy and pneumonectomy are usually prohibitive for this population. ${ }^{3}$ Consequently, upon diagnosis of various types and stages of tumors and after a comprehensive geriatric assessment (CGA), elderly patients have either received suboptimal therapy or have been frequently placed on best supportive care, while younger patients would receive optimal treatment for the same condition.

The advances in targeted therapy, coined precision oncology, and immunotherapy have opened the doors for systemic therapies with better toxicity profile and superior efficacy, as compared to standard cytotoxic chemotherapy. ${ }^{4}$ That encompasses selective estrogen receptor modulators or aromatase inhibitors associated with cyclin-dependent kinase inhibitors in breast cancer, anti-HER-2 therapies in breast and gastric cancer, tyrosine, and other kinase inhibitors for lung, renal cancer, melanoma, chronic myelogenous leukemia, gastrointestinal stromal tumors (GIST), anti-CD20 antibodies for B-cell lymphomas, among many other examples. Even more striking, the development of modern cancer immunotherapy, based on monoclonal antibodies targeting co-receptors involved in the modulation of the cancer-immune interaction, or immune-checkpoint inhibitors, which is now used to treat more than a dozen different types of cancer, has been shown to induce robust anti-tumor responses with a good tolerability in the elderly and frail, as compared to younger and healthier patients. ${ }^{5}$ With significant prolongation of progression-free survival and overall survival described for various cancers and rare cases of severe toxicities or deleterious effects on quality of life, immunotherapy now seems to lower the threshold even further in selecting elderly and frail patients for cancer treatment.

\section{OBJECTIVES}

To review the United States Food and Drug Administration (FDA) - approved targeted and immunotherapies, currently used in oncology and assess their safety and efficacy in the frail and the geriatric sub-population, addressing specific recommendations, when applicable.

\section{MATERIAL AND METHODS}

Validating the ever growing need for evidence-based recommendations on the most appropriate way to treat this subgroup of cancer patients, we conducted a review of prospective trials, retrospective analysis, and published meta-analysis evaluating immunotherapy and targeted therapy in PubMed database whose inclusion criteria comprises patients older than 65 years and with a performance status that could suggest a frailer individual (ECOG higher than 2).

\section{Immunotherapy}

Immunosenescence entails changes by which, during the process of ageing, the immune surveillance becomes progressively deficient, thus allowing cancers to develop. Physiologically, every cell is systematically exposed to damage and the organism responds by developing mechanisms that can either repair or destroy the abnormal clone. A tumor mass comprises not only cancerous cells, but also normal cells and a matrix that helps the development and stability of the mass, in addition to tumor infiltrating immune cells. This tumor microenvironment, and the understanding of the intricate relationship between normal and abnormal cells and how to target specific 
pathways has drastically changed the approach to cancer therapy. ${ }^{6}$

Out of all the hallmarks of cancer, chronic cell proliferation can be considered the essential driver of tumor maintenance. ${ }^{6}$ Immunotherapy acts by blocking receptors, or checkpoints, causing inhibition of apoptosis in cells with aberrant properties, thus stopping stimulatory proliferation signal. Immune checkpoint inhibitors $(\mathrm{ICl})$, a class of drugs that acts through restoration of immune pathways in order to destroy cancer cells, rekindle immune response to non-self-antigens by blocking two main inhibitory checkpoint receptors with drugs approved to date: cytotoxic T lymphocyte-associated antigen-4 (CTLA4) and programmed cell death protein 1 (PD-1), and its ligand (PD-L1). ${ }^{7}$ By blocking such receptors, ICI mediate immune response by either stimulating T-cell proliferation, activation, and differentiation, or by suppressing the downregulating effect tumor cells can accomplish via inhibitory signals. ${ }^{4}$

Over the past decade, the FDA has approved these medications for several types and stages of cancers. However, trials that have been designed to validate the efficacy of $\mathrm{ICI}$ have consistently enrolled patients with good performance status only, thus excluding the frail population from its eligibility criteria (and, consequently, a significant percentage of the elderly), making it challenging to find evidence-based recommendations in this situation. ${ }^{8,9}$ Based on the fact that immunotherapy has produced unprecedented results in various types of tumors, not only being more beneficial than standard chemotherapy, but also much less toxic, there has been significant interest when it comes to treating elderly or frail patients, mostly by extrapolating data from a younger and healthier population. ${ }^{10,11}$

However, comparison of functionality of the immune system of older and younger patients demonstrates an age-related decline in immune function. ${ }^{12}$ This decrement is multifactorial, due to both quantitative and qualitative alterations. T-cells decline in number and are more prone to have inhibitory pathways upregulated. ${ }^{13}$ The effect of the decline in immune function on the efficacy of $\mathrm{ICl}$ is still controversial. Nishijima et al. (2016) ${ }^{13}$ conducted a meta-analysis in order to evaluate response to $\mathrm{ICl}$ in the elderly, 4,275 patients from 8 randomized controlled trial were included, showing a similar benefit for younger and older cancer patients in regard to overall survival (OS: $\mathrm{HR}=0.75 ; 95 \% \mathrm{Cl}=0.68-0.82$ versus $\mathrm{HR}=0.73 ; 95 \%$ $\mathrm{Cl}=0.62-0.87){ }^{13}$

Data are still scarce and sometimes even conflicting as the same meta-analysis suggested a tendency of individuals over 75 years of age not deriving the same benefit from immunotherapy (OS: HR=0.86; $95 \% \mathrm{Cl}=0.41-1.83) .{ }^{13}$ Contrary to the hypothesis that immunosenescence may negatively affect the efficacy of $\mathrm{ICl}$ in the elderly, a Danish study conducted by Bastholt et al. (2019) ${ }^{14}$ demonstrated that patients with metastatic melanoma aged between 70 and
80 years had better outcomes with pembrolizumab compared to patients either younger than 70 years or older than 80 years. Median progression-free survival (PFS) was 10.3 months in the former, and 5.7 and 7.1 months in the last two age groups ( $p=0.032$ in multivariate analysis). Similarly, OS was significantly longer in patients aged between $70-80$ years (36.5 months), compared to the groups aged under 70 years (18.8 months) and over 80 years (20.2 months; $p=0.011) .{ }^{14}$ This study postulated the hypothesis that there may be an age group that still maintains a proper immune function and derive more benefit from $\mathrm{ICl}$ due to melanoma characteristics that may differ in older patients, such as higher ultraviolet exposure and consequently a higher tumor mutation burden.

We could not find prospective clinical trials of $\mathrm{ICI}$ stratifying patients according to CGA. A few prospective clinical trials were carried out to evaluate the efficacy and safety of immunotherapy in patients with Eastern Cooperative Group Performance Status Scale (ECOG PS) of $\geq 2$. CheckMate 817 , a phase 3B/4 trial, treated patients with NSCLC and ECOG PS of 2 with ipilimumab and nivolumab, a potentially more toxic combination, with results validating the safety (treatment-related adverse events grade 3 or 4 of $12 \%$ ) and efficacy (objective response rate of $25 \%$ ) of immunotherapy in a population with multiple comorbidities and poorer prognosis overall. The findings were similar to what would be expected in patients with an ECOG PS of 0-1.15

In the PePS2 study, patients with non-small cell lung cancer (NSCLC) and an ECOG PS of 2 were treated with pembrolizumab, regardless of PD-L1 expression. ${ }^{16}$ The median age was 72 years (IQR 65-75). Overall, $28 \%$ experienced toxicities and, although there were no deaths related to the use of immunotherapy, $10 \%$ had to discontinue treatment. This study showed an objective response rate of $11 \%$ in the PD-L1 negative group, 33\% in the 1-49\% PD-L1 group, and of $47 \%$ in the group with more than $50 \%$ of PD-L1 expression in tumor cells. All findings, in particular the latter, were again similar to what was described previously. In KEYNOTE-024, a trial with the same treatment in patients with PD-L1 expression $\geq 50 \%$ (but restricted to patients with ECOG 0 or 1 ), the response rate was $44.8 \%$ and grades 3-5 adverse events were present in $26.6 \%)^{11}$

In a phase 2 study treating cisplatin-ineligible urothelial cancer patients, IMvigor210, single-agent atezolizumab was given. ${ }^{17}$ Recruited patients had a median age of 73 years, $21 \%$ of the sample were aged over 80 years, and $20 \%$ had an ECOG PS 2 . Subgroup analysis were conducted in order to evaluate response rate, duration of response and median overall survival across individuals with different expressions of PD-L1 in tumor infiltrating cells. Results suggested a tendency in achieving durable responses, which translated in a higher median overall survival (15.9 months) when compared to first-line therapy (gemcitabine plus carboplatin: 9.3 months) for cisplatin-in- 
eligible patients and similar median overall survival rates (15.2-15.8 months) to historical controls treated with standard cisplatin-based chemotherapy.

Such studies corroborate the hypothesis that immunotherapy may be safe and effective in the context of a more fragile/older patient population. Accordingly, CheckMate 153, a phase 3B/4 study evaluating the safety of nivolumab as single agent in NLSCL patients who had advanced disease and poor PS, with a primary endpoint of incidence of treatment- related adverse effects of grades 3 to 5, demonstrated results in line with these observations. Population accrued consisted of 39\% ( $N=556)$ of individuals older than 70 years and 10\% (N=128) had an ECOG PS 2. Results indicated that this drug is active (median OS in the general population $=9.1$ months; in the population of 70 years or older $=10.3$ months), though results in the ECOG PS 2 population were disappointing, with a median OS of 4.0 months. The drug rendered a fairly similar toxicity profile in older and frailer cohort when compared to the overall population (grade 3-5 adverse events: 6 and 9\%, respectively, with one grade 5 event - intestinal perforation in a 70 years-old patient with ECOG PS 1). ${ }^{18}$

We found only one prospective study evaluating the multi-prognostic index (MPI) in patients about to initiate immunotherapy for several solid tumors. Though groups were not balanced between tumor types, disease burden and treatment specifications, patients had a progressively shorter OS from the first to third quartile of the MPI score, with patients in the latter having a risk of death five times higher than those in the former..$^{19}$ Interestingly, only $11.4 \%$ of patients in this study were classified as having an ECOG PS of 2 or 3, which raises the question of this scale's role in distinguishing frailer patients.

\section{Targeted therapy}

A better understanding of genetic and epigenetic mechanisms implicated in the development of cancer paved the way for the incorporation of a plethora of molecular-targeted therapies. Since the early publications addressing the efficacy of imatinib in GIST, 20 Paul Ehrlich's "Zauberkugel" concept adapted to oncology was brought to daily practice, with an unprecedented impact on the management of distinct solid malignancies. ${ }^{21,22}$ For instance, lung cancer was reclassified in molecularly-defined subgroups based upon the presence of EGFR, ALK, and ROS1 genetic alterations, among others, each allowing for the use of specific targeted-agents. A similar transition occurred in melanoma (with tumors harboring BRAF mutations), breast cancer (with HER-2 amplifications), colorectal cancer (with KRAS and BRAF mutations), among others. More recently, the so-called agnostic therapies were made available for different types of solid tumors that share similar genetic abnormalities, irrespectively of the histology or site of origin. ${ }^{23}$

Amid this effervescence of new treatment options and the undoubtful positive impact in outcomes, a relevant question is whether exploring these targets in the elderly results in similar efficacy and tolerability when compared to the population included in clinical trials, in which individuals at more advanced ages are often underrepresented.

It is important to note that the distribution of these targets is not uniform across different age subgroups. In non-small cell lung cancer, ALK mutations are enriched among those younger than 50 years, and rarely identified in patients older than 60 years, with a similar, yet less pronounced trend for EGFR mutations. ${ }^{24}$ Likewise, BRAF V600E mutations associated with sensitivity to MAPK pathway blockade in melanoma are typically found in younger patients and in tumors arising in areas not chronically damaged by ultraviolet radiation. ${ }^{25}$ These findings highlight that, indeed, the molecular characteristics of solid tumors varies with age, posing an initial challenge to extrapolate the use of targeted therapies in older individuals.

Ageing, however, does not seem to negatively affect the efficacy of these agents and should not be a deterrent for clinical decision making, although selection and publication biases may limit the interpretation of the data. In separate studies that interrogated the efficacy of sunitinib, sorafenib or axitinib in advanced renal cell carcinoma, similar outcomes were described for those older than $65-70$ years. ${ }^{26-29}$ In NSCLC, erlotinib yielded similar response rates, PFS, and OS improvements in older subgroups. ${ }^{30,31}$ More recently, Bedas et al. (2019) 32 reported on 53 consecutive ALK-positive NSCLC patients treated with crizotinib, ceritinib, and alectinib, and suggested similar efficacy in the elderly using a 65 years of age cutoff. ${ }^{32}$ In BRAF-mutant advanced melanoma, the efficacy of dabrafenib and trametinib or vemurafenib and cobimetinib was not influenced by age in separate trials. $^{33,34}$ Interestingly, older age was among the factors associated with prolonged duration of PFS and OS in a pooled analysis of two randomized trials that included patients treated with dabrafenib and trametinib. ${ }^{34}$

Nevertheless, despite evidence implying a similar efficacy, both the drug metabolism and the safety profile are distinct in the elderly population, resulting in an increased rate of adverse events and a higher proportion of treatment discontinuations due to toxicities. Also, the perception and tolerance to low-grade (grades 1-2) adverse events may be different, especially if persistent. As examples, several randomized studies and retrospective series suggested a higher rate of fatigue, decreased appetite, hematological toxicities, specific dermatological adverse events, elevated liver enzimes, and diarrhea associated with small molecules such as sunitinib, sorafenib, imatinib, erlotinib, and mTOR inhibitors (everolimus). ${ }^{35}$ Of note, cardiac ejection fraction impairment was more pronounced in elderly patients treated with dabrafenib and trametinib or vemurafenib and cobimetinib for advanced melanoma and HER-2 directed therapy with trastuzumab for breast cancer. ${ }^{33,34}$ 
Another major concern associated with the use of targeted therapies in elderly patients results from the potential drug interactions, as comorbidities are often present when the diagnosis of cancer is made and many drugs share similar metabolic pathways, particularly mediated through the cytochrome P450 complex. Hence, a detailed pharmacologic reconciliation is strongly advised before starting targeted agents for this subpopulation.

\section{DISCUSSION}

Although elderly people are known to host the vast majority of cases of cancer diagnosed every year, there is a trend towards an underrepresentation of elderly and especially frail patients among those accrued to clinical trials. Two conferences held by the Cancer and Aging Research Group (CARG), together with the National Institute of Aging (NIA) and the National Cancer Institute (NCI), in 2010 and 2012, focused on better assessing epidemiology, tumor biology, population characteristics, pertinent endpoints, and overall comprehension of the burden of cancer in this specific subpopulation. This effort aimed to provide a model through which evidence-based medicine, conceived particularly for the elderly/frail, could be performed. ${ }^{36}$

In a retrospective analysis of $\mathrm{NCl} 2003$ database, Lewis et al. (2003) $)^{37}$ emphasized this paradox by stating that they comprehend $60 \%$ of all new cases of cancer diagnosed yearly, yet only represent about $32 \%$ of assigned participants in phase II and III trials. This discrepancy was more prominent in trials designed for early-stage cancers. The researchers estimated that if trials would have less strict eligibility criteria, the elderly would comprise, on average, $60 \%$ of all patients. ${ }^{37}$

According to a more recent update of the SEER Database, patients aged between 65 and 74 years comprised $27.6 \%$ of cancers of any site, 75 to 84 represented $18.3 \%$ and $8.1 \%$ were 85 years old or older. However, when the rates of cancer-related mortality by age group were stratified, those who were older when the disease was diagnosed had worse outcomes. ${ }^{38}$

It is also important to debate whether the value of endpoints chosen in clinical trials should be the same for distinct age groups. Although OS, PFS and response rates remain relevant when addressing the efficacy of interventions in the elderly, other patient-centered outcomes could potentially vary and have a different weight in this complex decision-making process, including quality of life, cognitive, and functional assessments, burden to caregivers, and patient's preferences and expectations. ${ }^{39}$ Furthermore, there is a lack of controlled studies to fully explore the scenario of immunotherapy in the elderly. This is an area where numerous factors could determine efficacy to treatment, including tumor mutations burden, lymphocyte infiltration, HLA heterogeneity, tumor heterogeneity, among others. ${ }^{5}$ How these factors interact to determine sensitivity in the elderly is unknown. There is also need for more real-world data, since even clinical trials specifically designed for an elderly population tend to select patients with a lower comorbidity score and better performance status.

Resulting from decades of experience with chemotherapy and its prohibitive toxicities in elderly and especially in frail patients, a performance-focused rather than age-based recruitment criteria was initially believed to be a better indication for tolerability. However, frailty was subsequently shown not to correlate with the standard ECOG PS scale or age alone in a linear fashion. ${ }^{40}$ Since then, although the assessment of frailty became standard to aid therapeutic choices in clinical practice, no trials reported to date have utilized geriatric frailty scores to prospectively stratify patient eligibility. The CGA and shorter screening tools for frailty have taken center stage in recent years to better assist decision-making regarding treatment for the elderly. ${ }^{41}$ Even though these tools have not been sufficiently validated in the scenario with less toxic targeted therapies and modern immunotherapy, they still remain the standard tool for proper management of frail patients.

With results described above suggesting an overall comparable efficacy of modern antineoplastic therapies across several tumor types when compared to younger patients, with acceptable toxicities across the board compared to cytotoxic chemotherapy in the elderly and frail patients, the very decision to place such patients on exclusive palliative care can no longer be made based on age or frailty alone, without a broader molecular and immune profiling of the tumor. The historical conception of medical oncologists pushing for palliative treatments for elderly or frail patients with advanced disease does not apply to the current clinical context any longer. Withholding a targeted therapy or immune therapy from an eligible patient based solely on a more adverse clinical condition is not standard procedure, except if the patient expressively refuses to be treated, after a thorough explanation of what these treatment modalities entail. The lesser toxicity and the higher efficacy should and has in fact encouraged medical oncologists to administer these therapies earlier in the course of the disease and in a higher-risk population, like elderly and frail patients, often witnessing profound responses and improvement in both quantity and, most importantly, quality of life.

This review has some limitations. As there are no randomized trials specifically designed to evaluate the efficacy and safety of immune and targeted therapy, the current interpretation is restricted to subgroup analysis. There is a natural selection bias of a fitter elderly population, as inclusion criteria encompasses performance status rather than age. This could promote a significant obstacle in representing this population, thus precluding broad conclusions to be inferred based on a highly selected group of patients. However, no trials found a specifically worse clinical course due to age alone, as it seems to be observed in the authors' own clinical experience. 


\section{CONCLUSION}

Advanced age and frailty do not seem to determine a lower efficacy nor to predict prohibitive toxicities from targeted therapies or immunotherapy. Traditional assessment tools for frailty have not been formally validated in patients receiving these new systemic treatment modalities. When dealing with a subgroup of patients who represent up to $60 \%$ of diagnosed cases of cancer, though account for only one third of the studied population in recent trials of precision oncology, one can establish that further studies are warranted in the elderly and frail to gain more insight on the field. The very threshold for decision regarding placement on palliative care may need to be revisited in the era of targeted therapies and modern immunotherapy, with a more liberal approach and comprehensive assessment in the elderly and frail.

\section{ACKNOWLEDGMENTS}

None.

\section{CONFLICT OF INTEREST STATEMENT}

The authors listed below certify that they have no involvement in any organization or entity with any financial interest (such as honoraria; educational grants; participation in speakers' bureaus; membership, employment, consultancies, stock ownership, or other equity interest; and expert testimony or patent-licensing arrangements), or non-financial interest (such as personal or professional relationships and affiliations) in the subject matter discussed in this manuscript.

\section{Juliana Beal}

Nothing to disclose.

\section{Gustavo Schvartsman}

Participation in speakers' bureaus: Bristol-Myers Squibb, Novartis, Merck Sharp and Dohme, Sanofi, AstraZeneca, Roche, Amgen. Consultancies: AstraZeneca, Roche, Merck Sharp and Dohme.

\section{Rodrigo Munhoz}

Honoraria: Bayer, BMS, Novartis, Merck-Serono, MSD, Roche, Sanofi. Participation in speakers' bureaus: BMS, Novartis, Merck-Serono, MSD, Roche, Sanofi. Consultancies: Bayer, Merck-Serono, Roche, Sanofi.

\section{Theodora Karnakis}

Nothing to disclose.

\section{Rafael Kaliks}

Participation in speakers' bureaus: Astra Zeneca; Novartis; Pfizer; Roche. Consultancies: Astra Zeneca.

\section{REFERENCES}

1. White MC, Holman DM, Boehm JE, Peipins LA, Grossman M, Henley SJ. Age and cancer risk: a potentially modifiable relationship. Am J Prev Med. 2014 Mar;46(3 Suppl 1):S7-S15.
2. Wildiers $\mathrm{H}$, Heeren $\mathrm{P}$, Puts $\mathrm{M}$, Topinkova $\mathrm{E}$, Janssen-Heijnen ML, Extermann M, et al. International Society of Geriatric Oncology consensus on geriatric assessment in older patients with cancer. J Clin Oncol. 2014 Aug;32(24):2595-603.

3. Soto-Perez-de-Celis E, Li D, Yuan Y, Lau YM, Hurria A. Functional versus chronological age: geriatric assessments to guide decision making in older patients with cancer. Lancet Oncol. 2018 Jun;19(6):e305-e16.

4. Darvin P, Toor SM, Nair VS, Elkord E. Immune checkpoint inhibitors: recent progress and potential biomarkers. Exp Mol Med. 2018 Dec;50(12):1-11.

5. Helissey C, Vicier C, Champiat S. The development of immunotherapy in older adults: new treatments, new toxicities? J Geriatr Oncol. 2016 Sep;7(5):325-33.

6. Hanahan D, Weinberg RA. Hallmarks of cancer: the next generation. Cell. 2011 Mar;144(5):646-74.

7. Elias R, Karantanos T, Sira E, Hartshorn KL. Immunotherapy comes of age: immune aging \& checkpoint inhibitors. J Geriatr Oncol. 2017 May;8(3):229-35.

8. Finn RS, Ryoo BY, Merle P, Kudo M, Bouattour M, Lim HY, et al. Pembrolizumab as second-line therapy in patients with advanced hepatocellular carcinoma in KEYNOTE-240: a randomized, double-blind, phase III trial. J Clin Oncol. 2020;38(3):193-202.

9. Ready N, Hellmann MD, Awad MM, Otterson GA, Gutierrez M, Gainor JF, et al. First-Line nivolumab plus ipilimumab in advanced non-small-cell lung cancer (CheckMate 568): outcomes by programmed death ligand 1 and tumor mutational burden as biomarkers. J Clin Oncol. 2019 Apr;37(12):992-1000.

10. Mok TSK, Wu YL, Kudaba I, Kowalski DM, Cho BC, Turna HZ, et al. Pembrolizumab versus chemotherapy for previously untreated, PD-L1-expressing, locally advanced or metastatic non- smallcell lung cancer (KEYNOTE-042): a randomised, open-label, controlled, phase 3 trial. Lancet. 2019;393(10183):1819-30.

11. Reck M, Rodriguez-Abreu $D$, Robinson AG, Hui R, Csoszi T, Fulop A, et al. Pembrolizum$a b$ versus chemotherapy for PD-L1-positive non-small-cell lung cancer. N Engl J Med. 2016 Nov;375(+19):1823-33.

12. Elias R, Morales J, Rehman Y, Khurshid H. Immune checkpoint inhibitors in older adults. Curr Oncol Rep. 2016 Aug;18(8):47.

13. Nishijima TF, Muss HB, Shachar SS, Moschos SJ. Comparison of efficacy of immune checkpoint inhibitors (ICls) between younger and older patients: a systematic review and meta- analysis. Cancer Treat Rev. 2016;45:30-7. 
14. Bastholt L, Schmidt H, Bjerregaard JK, Herrstedt J, Svane IM. Age favoured overall survival in a large population-based Danish patient cohort treated with anti-PD1 immune checkpoint inhibitor for metastatic melanoma. Eur J Cancer. 2019 Aug;119:122-31.

15. Barlesi F, Audigier-Valette C, Felip E, Ciuleanu T, Jao K, Rijavec E, et al. OA04.02 CheckMate 817: first-line nivolumab + ipilimumab in patients with ECOG PS 2 and other special populations with advanced NSCLC. J Thorac Oncol. 2019 Oct;14(10):S214-S5.

16. Middleton G, Brock K, Savage J, Mant R, Summers $Y$, Connibear J, et al. Pembrolizumab in patients with non-small-cell lung cancer of performance status 2 (PePS2): a single arm, phase 2 trial. Lancet Respir Med. 2020 Sep;8(9):895-904.

17. Balar AV, Castellano D, O'Donnell PH, Grivas $P$, VukyJ, Powles T, et al. First-line pembrolizumab in cisplatin-ineligible patients with locally advanced and unresectable or metastatic urothelial cancer (KEYNOTE-052): a multicentre, single-arm, phase 2 study. Lancet Oncol. 2017 Nov;18(11):1483-92.

18. Spigel DR, McCleod M, Jotte RM, Einhorn L, Horn L, Waterhouse DM, et al. Safety, efficacy, and patient-reported health-related quality of life and symptom burden with nivolumab in patients with advanced non-small cell lung cancer, including patients aged 70 years or older or with poor performance status (CheckMate 153). J Thorac Oncol. 2019 Sep;14(9):1628-39.

19. Sbrana A, Antognoli R, Pasqualetti G, Linsalata G, Okoye C, Calsolaro V, et al. Effectiveness of multi-prognostic index in older patients with advanced malignancies treated with immunotherapy. J Geriatr Oncol. 2020 Apr;11(3):503-7.

20. Joensuu H, Roberts PJ, Sarlomo-Rikala M, Andersson LC, Tervahartiala P, Tuveson D, et al. Effect of the tyrosine kinase inhibitor STI571 in a patient with a metastatic gastrointestinal stromal tumor. N Engl J Med. 2001 Apr;344(14):1052-6.

21. Garraway LA. Genomics-driven oncology: framework for an emerging paradigm. J Clin Oncol. 2013 May;31(15):1806-14.

22. Zehir A, Benayed R, Shah RH, Syed A, Middha S, Kim $\mathrm{HR}$, et al. Mutational landscape of metastatic cancer revealed from prospective clinical sequencing of 10,000 patients. Nat Med. 2017 Jun;23(6):703-13.

23. Drilon A, Laetsch TW, Kummar S, DuBois SG, Lassen UN, Demetri GD, et al. Efficacy of larotrectinib in TRK fusion-positive cancers in adults and children. N EngI J Med. 2018 Feb;378(8):731-9.

24. Suidan AM, Roisman $L$, Rozenblum AB, Ilbouze M, Dudnik E, Zer A, et al. Lung cancer in young patients: higher rate of driver mutations and brain involvement, but better survival. J Glob Oncol. 2019 May;5:1-8.
25. Cancer Genome Atlas Network. Genomic classification of cutaneous melanoma. Cell. 2015 Jun;161(7):1681-96.

26. Hutson TE, Bukowski RM, Rini BI, Gore ME, Larkin JM, Figlin RA, et al. Efficacy and safety of sunitinib in elderly patients with metastatic renal cell carcinoma. Br J Cancer. 2014 Mar;110(5):1125-32.

27. Brunello A, Basso U, Sacco C, Sava T, Vivo R, Camerini $A$, et al. Safety and activity of sunitinib in elderly patients ( $>70$ years) with metastatic renal cell carcinoma: a multicenter study. Ann Oncol. 2013 Feb;24(2):336-42.

28. Eisen T, Oudard S, Szczylik C, Gravis G, Heinzer $H$, Middleton R, et al. Sorafenib for older patients with renal cell carcinoma: subset analysis from a randomized trial. J Natl Cancer Inst. 2008 Oct;100(20):1454-63.

29. Rini BI, Escudier B, Tomczak P, Kaprin A, Szczylik C, Hutson TE, et al. Comparative effectiveness of axitinib versus sorafenib in advanced renal cell carcinoma (AXIS): a randomised phase 3 trial. Lancet. 2011 Nov;378(9807):1931-9.

30. Merimsky O, Cheng CK, Au JS, Von Pawel J, Reck M. Efficacy and safety of first-line erlotinib in elderly patients with advanced non-small cell lung cancer. Oncol Rep. 2012 Aug;28(2):721-7.

31. Wheatley-Price P, Ding K, Seymour L, Clark GM, Sheperd FA. Erlotinib for advanced non-small-cell lung cancer in the elderly: an analysis of the National Cancer Institute of Canada Clinical Trials Group Study BR.21. J Clin Oncol. 2008 May;26(14):2350-7.

32. Bedas A, Peled N, Rabinovich NM, Mishaeli M, Schochat T, Zer A, et al. Efficacy and safety of ALK tyrosine kinase inhibitors in elderly patients with advanced alk-positive non-small cell lung cancer: findings from the real-life cohort. Oncol Res Treat. 2019;42(5):275-82.

33. Ascierto PA, McArthur GA, Dréno B, Atkinson V, Liszkay G, Di Giacomo AM, et al. Cobimetinib combined with vemurafenib in advanced BRAF(V600)-mutant melanoma (coBRIM): updated efficacy results from a randomised, double-blind, phase 3 trial. Lancet Oncol. 2016 Sep;17(9):1248-60.

34. Robert C, Grob J, Stroyakovskiy D, Karaszewska B, Hauschild A, Levchenko E, et al. Five-year outcomes with dabrafenib plus trametinib in metastatic melanoma. N Engl J Med. 2019 Aug;381(7):626-36.

35. Daste A, Chakiba C, Domblides C, Gross-Goupil M, Quivy A, Ravaud A, et al. Targeted therapy and elderly people: a review. Eur J Cancer. 2016 Dec;69:199-215.

36. Hurria A, Dale W, Mooney M, Rowland JH, Ballman KV, Cohen $\mathrm{HJ}$, et al. Designing therapeutic clinical trials for older and frail adults with cancer: U13 conference recommendations. J Clin Oncol. 2014 Aug;32(24):2587-94. 
37. Lewis JH, Kilgore ML, Goldman DP, Trimble EL, Kaplan R, Montello MJ, et al. Participation of patients 65 years of age or older in cancer clinical trials. J Clin Oncol. 2003 Apr;21(7):1383-9.

38. Howlader N NA, Krapcho M, Miller D, Brest A, Yu M, Ruhl J, Tatalovich Z, Mariotto A, Lewis DR, Chen HS, Feuer EJ, Cronin KA. Surveillance, epidemiology, and end results (SEER) Program SEER*Stat Database: Mortality - Total U.S. (1969-2016). Bethesda: National Cancer Institute (NIH); 2019.

39. Wildiers $H$, Mauer M, Pallis A, Hurria A, Mohile SG, Luciani A, et al. End points and trial design in geriatric oncology research: a joint European organisation for research and treatment of cancer--Alliance for Clinical Trials in Oncology--International Society Of Geriatric Oncology position article. J Clin Oncol. 2013 Oct;31(29):3711-8.
40. Soubeyran P, Bellera C, Goyard J, Heitz D, Cure H, Rousselot $\mathrm{H}$, et al. Screening for vulnerability in older cancer patients: the ONCODAGE prospective multicenter cohort study. PLoS One. 2014 Dec;9(12):e115060.

41. Owusu C, Koroukian SM, Schluchter M, Bakaki P, Berger NA. Screening older cancer patients for a comprehensive geriatric assessment: a comparison of three instruments. J Geriatr Oncol. 2011 Apr;2(2):121-9.

42. Luo J, Rizvi H, Egger JV, Preeshagul IR, Wolchok JD, Hellman MD. Impact of PD-1 blockade on severity of COVID19 in patients with lung cancers. Cancer Discovery. 2020 May 12; [Epub ahead of print]. DOI: https://doi.org/10.1158/2159-8290.CD-20-0596 